\title{
We Are Not Alone: Conceptualizing People-Things Relationship in Oromo Community in North America
}

\author{
Bula Sirika Wayessa ${ }^{1}$ \\ State University of New York New Paltz
}

\begin{abstract}
This study presents that in Oromo society, objects and non-human organisms have agency that affects how human agents interact with them. The objects have representations and they store information about themselves and their human partners. For example, clay, considered to be vulnerable, is treated in a fashion similar to a human infant. Such beliefs have direct bearing on pottery production and consumption. As well, objects are considered to be 'family' members, traveling with their human counterparts to various corners of the world. In North America, the diaspora Oromo's social and family gatherings are accompanied by objects brought from their country of origin. During gatherings, people communicate with the objects to retrieve memories of the past. In the new setting, the objects serve as active agents, adding color and flair to celebrations.

Keywords: Agency, Anchote, Diaspora Oromo, North America, Objects.
\end{abstract}

\section{Introduction}

Social theorists have argued that objects and non-human organisms share an agency that affects how humans interact with them (Robb, 2005; van Oenen, 2011). Because "people extend their social relationships to non-human agents, properties have been exchanged and collectives formed" (Latour, 1999, p. 198). Non-human agents possess secondary agency: the cultural perception that certain objects embody the power to act in particular ways or that require humans to act in certain ways with these materials (e.g., Akhtar, 2005; Caronia \&Mortari, 2015; Gardner, 2007; Gell, 1998, Gosden, 2005; 2012; Kim 2016; Latour, 1999, 2005; Sillar, 2004; 2009; van Oenen, 2011; Aydin, \& Ozfidan, 2014). In this sense, objects are actively used in social and individual creation in which they are directly constitutive of our understanding of self and others (Olsen, 2003, p. 91). Studies also show that immigrants use material objects to connect to the places they left behind (Abu-Ghazaleh, 2013; Akhtar, 2005; Kim, 2016).

This research examines the perception of the Oromo, in North America, regarding agency of objects and their relationship with human agency. The Oromo are speakers of Afaan Oromoo, an eastern highland Cushitic branch of the Afro-Asiatic language family (Ehert, 2002; Greenberg, 1955). They are the largest ethnolinguistic group in northeast Africa. Although the majority of Oromo live in the Oromia Regional State, a significant number live in Wambara and Kamise, in the Amhara region in the central Ethiopian highlands, and in the Rayya and Asabo areas of Tigray State, in the northern highlands. Oromo are also found in Kenya and Somalia (Hassan, 1991; Magersa, 1992).

The Oromo believe in one Supreme Being, Waaqa, which literally means God (Bulcha, 2011; Legesse, 1973; Melba, 1988; Ta'a, 2006). Waaqa is the creator (uumaa) of all creatures (uumama) (Melba, 1988; Ta'a, 2006). Despite the introduction of Christianity and Islam into the Oromia, the indigenous religious practices are upheld. Traditional ceremonies, such as the annual Irreessaa(Irreechaa) festivals, the Oromo version of Thanksgiving, continue to be practiced. At present, the Irreessaa festival is gathering whereby Oromo people from different religious backgrounds participate in an all-encompassing event viewed as an identity marker shared by Oromo society (Wayessa, 2016).

The Oromo practice a mixed economy. Cattle are widely bred both for symbolic and economic purposes. Symbolically, they serve as a source of prestige and a sign of Waaqa's blessing. Economically, cattle are a source of natural fertilizer and food; oxen serve as major draught animals in farming. In addition to cereal grains, tuber crops such as anchote, Oromo potatoes, yam, and taro, are widely cultivated. Coffee is the major cash crop in many regions of Oromia. Crafts, notably woodcarving, weaving, tanning, iron smelting and pottery-making, are also important in the society's contemporary economy. Craft products are major sources of livelihood for the artisan society who have insufficient or no land to support their families' needs. More important, craftwork, including pottery-making and basketry, assist rural artisan women in gaining partial independence from their husbands in meeting basic family needs. An inseparable

\footnotetext{
${ }^{1}$ Department of Black Studies

Email: wayessa.bula2009@gmail.com
} 
relationship between agriculture and handicraft technology exists in this region. It is certain that if there were no agriculture, demand for these handicraft products would not exist, and vice versa. For instance, agricultural activities cannot be undertaken without farm implements that are products of the local handicraft workers. Essentially, agriculture and crafts have a symbiotic relationship. Such relationships between different economic sectors have structured the Oromo worldviews and philosophy of life, both locally and globally.

While the majority of the Oromo live in Ethiopia, a significant number also live in North America, Europe and Asia (Kumsa, 2006; Servan, 2008; Wayessa, 2016). Although the presence of the Oromo in North America can be traced back to the early $20^{\text {th }}$ century, the Oromo began to massively migrate to this continent after 1991. Some of the migrants left their country of origin for political reasons and rarely travel back. In the new world, immigrants have forged mechanisms that appease their souls by forming their own community. They recount their experiences from their homeland and know that meeting individuals, alone, cannot make up a community. In the Oromo tradition, a house has representation, beyond being a place to live. A house's location and its direction of windows and doors are informed by their life-philosophy which, in turn, is framed by a people-objects relationship. Similarly, regardless of the prevailing differences between housing styles of Ethiopia and North America, they have recreated an environment in which they can live comfortably with the things that migrated with them. The objects are sources of both individual and community memories. Informed by the theory of agency of things, this paper sets out to explore the role of objects, with special emphasis on pottery, tuber crop and fabrics, in connecting Oromo immigrants in North America to one another and to their country of origin.

\section{Data Collection and Analysis}

Qualitative data for this study was collected through interviews and observations and captured through note taking and video recording. In the research, semi-structured interviews were used. DiCiccoBloom and Crabtree (2006) state that the semi-structured interview approach allows researchers to probe individuals' stories. Interviews were held in my native language, Afaan Oromoo. For the study, 50 individuals were interviewed in the summers of $2013,2014 \& 2015$. The interviews were held face-to-face at home, on the telephone and at social gatherings. The participants included married and unmarried members of the community, from different religious backgrounds, with an age range between 30 and 60 . The participants were designated as knowledgeable by their community and came highly recommended to me. The participants were asked to identify the objects they owned, how they acquired them and why they wanted to have the objects with them. The observations were held at Oromo community meetings, the Irreessaa festival, as well as in their respective homes. I observed the items that accompanied the social gatherings and the interaction between the items and people during the undertakings. Observations also included noting the way the objects were used, how they were displayed and what their interactions were with non-indigenous objects.

At the end of every day field-work, the participants' responses were read and reviewed to deepen understanding (McCracken, 1988).Familiarity with data also facilitates organizing research for final analysis and to recapture data gap (Graneheim \& Lundman 2004). Each participant was consulted at least twice to ensure consistency in their responses and for a follow-up interview. Finally, study findings were presented and conclusions drawn.

\section{Results}

The study reveals that in the Oromo society things, like humans, have agency. People communicate with things; the two groups negotiate and coexist. This finding concurs with similar studies (Caronia \& Mortari, 2015; Kim, 2016; Latour, 1999; Wayessa, 2015) conducted. The study also shows that Oromo immigrants use material culture to connect them to their homeland and to reintegrate lives and memories they had back home. Abu-Ghazaleh's (2013) study, conducted among Palestinians in North America, shows a similar scenario.

\section{Oromo society and the agency of things}

Agency of human beings often manifests through the aims individuals set and the ways they work to achieve said aims (Dobres\& Robb, 2000; Sillar, 2009). The actions are usually informed and constrained by the social structures they are founded in that, in turn, reproduce the structures (Bourdieu, 1977; Giddens, 1984). One of the structures that may limit human agency is the agency that objects possess. According to Olsen (2003, p. 88), 'things, objects, landscapes, possess 'real' qualities that affect and shape both our 
perception of them and our cohabitation with them." Objects with specific forms and designs manipulate people to reproduce themselves (Gell, 1998; Gosden, 2005). In other words, artifacts have their own forms and styles through which they shape the experience, memories and lives of people (Knappett, 2012; Sillar, 2009). As a result, objects are "not always seen as passive and people as active" (Gosden, 2005, p.194). In the Oromo society, every object, including land, plays an active role in the community's day-to-day socioeconomic life. The people talk with the objects and the objects, in turn, communicate with the people as need arises. The communication is not always smooth, but rather, may involve resistance. The conflict, however, does not break the link between the groups for neither can exist independently.

The human-things relationship is clearly manifested in pottery. Pottery technology, as a social practice, is associated with other areas of production activities, including processing cereal grains for baking bread and tubers for steaming. The skills and vocabulary used in these activities are transferred to and used in pottery-making. In this situation, pottery technology cannot be singled out from the rest of the social practices and assumed to be framed by performance requirements that tend to be universal in nature. During pottery production, the potters' technological choices are determined by other social practices, rather than solely by environmental factors. For this reason, pottery technology is the result of complex relationships among materials and between materials and people. As a result, it is misleading to polarize the "world of materials on the one hand and culture on the other, with the former acted upon by the latter" (Knappet, 2014, p. 4702).

Technology connects people and the objects that they manufacture, symbolically and literally (Dobres, 2000). Many researchers have demonstrated that people's social identities are entangled with the objects that they produce and consume (e.g., Dobres, 2000; Gell, 1998; Knappett, 2012; Olsen, 2003, 2012; Robb, 2005; Sillar, 1996, 2009). Potters transform raw materials from a natural state into a cultural object (David, Sterner \&Gavua, 1988). In the course of production, consumption and discard, pottery comes to embody social meaning. During daily practice, the meanings embodied in pots are actively engaged in social interactions and in interactions between people and pots (Gosden, 2005, Sillar, 1996, 2009).

In Ethiopia, the social identity of potters and their treatment within their community is based on how their occupation is socially perceived. In the Oromo society, a piece of pottery is more than a functional object. Pottery is perceived to have agency in terms of its capacity to embody spirits and certain deities, and in its need for specific types of human behaviors. For example, pottery is important in humanhuman social interactions, in addition to their functional uses in cuisine. In some interactions between pots and people, the boundaries between people and pots become blurred (David, Sterner \&Gavua, 1988; Gosselain, 1999; Wayessa, Lyons\&Kooyman, 2015). Because of the strong relationship they have, pots and people move together to new destinations. This becomes clear from the fact that, currently, the Oromo in North America possess pots they transported from Ethiopia.

One of the pottery objects people typically travel with is a coffee pot (jabanaa). The majority of the people interviewed had at least one coffee pot at home. Green grass surrounds the place where the woman who serves the coffee sits. Grass symbolizes life and prosperity; an element presents in all their public rituals, including funerals and a prayer of remembrance. On these occasions, grass is spread on the grave and its color, representing fertility, is perceived as the manifestation of Waaqa's blessings. In addition, coffee has representation. According to Oromo tradition, the first coffee plant sprouted from Waaqa's tears. As a result, during the coffee ceremony, people pray for Waaqa's blessings. Coffee roasting, in turn, is equated with slaughtering animals and the "pops" of coffee beans during roasting is linked emblematically with yelling. This is manifested in the Oromo proverb, buna lubbuuf xaaxa'u wari naatolii kadhatu, which means, "coffee beans pop up for its soul but a family prays for fortune" (Wayessa, 2016).

Back home, children are exposed to the coffee ceremony from an early age, as a forum used by elders to share proverbs and legends of the society. In doing so, the parents customize their children to a ritual that ensures the reproduction of the traditions as a social practice. The children find themselves tied to the coffee tradition that, of course, sustains the practices to date. In the diaspora, in addition to serving to enculturate children, the coffee ceremony is used as an avenue to share memories and experiences. The presence of the coffee pot, coffee table and green grasses helps them to sense the social life and essence of their country of origin. The ritual renews their spirits.

A related agency is seen through the representation of the African indigenous tuber known as anchote. Oromo oral traditions suggest that wild anchote was transplanted to home gardens to make it available for the women who suffered exhaustion and fatigue when in labor. The society associates anchote with fertility, and anthropomorphizes the tuber as fira deessuu, which means 'a relative of fertile women.'It 
is considered as the best postnatal meal to help women recover from postnatal ailments. Tubers and their cultivation are also seen in other connections with women. For instance, the plant with an edible underground organ is associated with a pregnant woman. This symbolism is important in controlling the time for harvesting. A woman gives birth when the fetus is matured and can endure the stress of the external physical environment. Analogous to this, a farmer is required to wait for the tubers to mature to harvest them. Prematurely harvested tubers are reported as unable to survive steaming preparation temperatures, thereby losing their natural flavor.

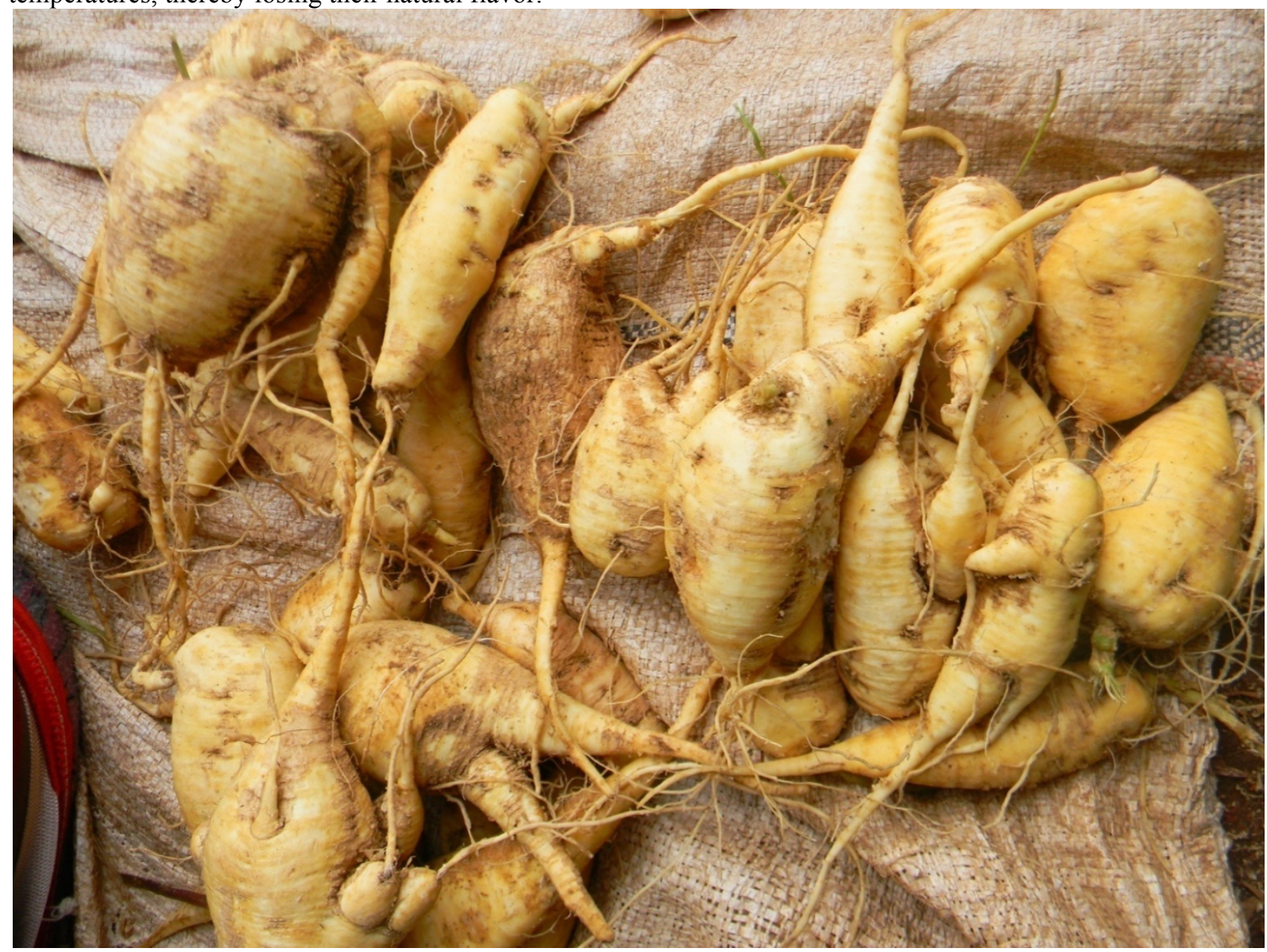

Figure 1. Anchote for sale in Gimbi town, a major supplier of the tuber in Oromia, Ethiopia.

Likewise, cultivating the desirable tubers is equated with raising children (See Figure 1). This symbolism becomes clear in the Oromo saying, "muka hundeen minyaa'u ijisaa minyaa'a", which translates as, "the tree with a sweet root produces a sweet fruit." Parents raise children and cultivate in their children what they believe to be acceptable behavior. Root crops are associated with human parents and 'parents' of all other crops because they form the foundation for seeds, leaves and other edible parts of domestic and wild plants. This perception is also expressed in the Oromo proverb, "muktii fiixeen nama hinbaatu, hundeetu nama baata malee," which means, "it is not a tree tip that bears a person but its root." This implies that even though children are important, parents constitute the family's foundation. 


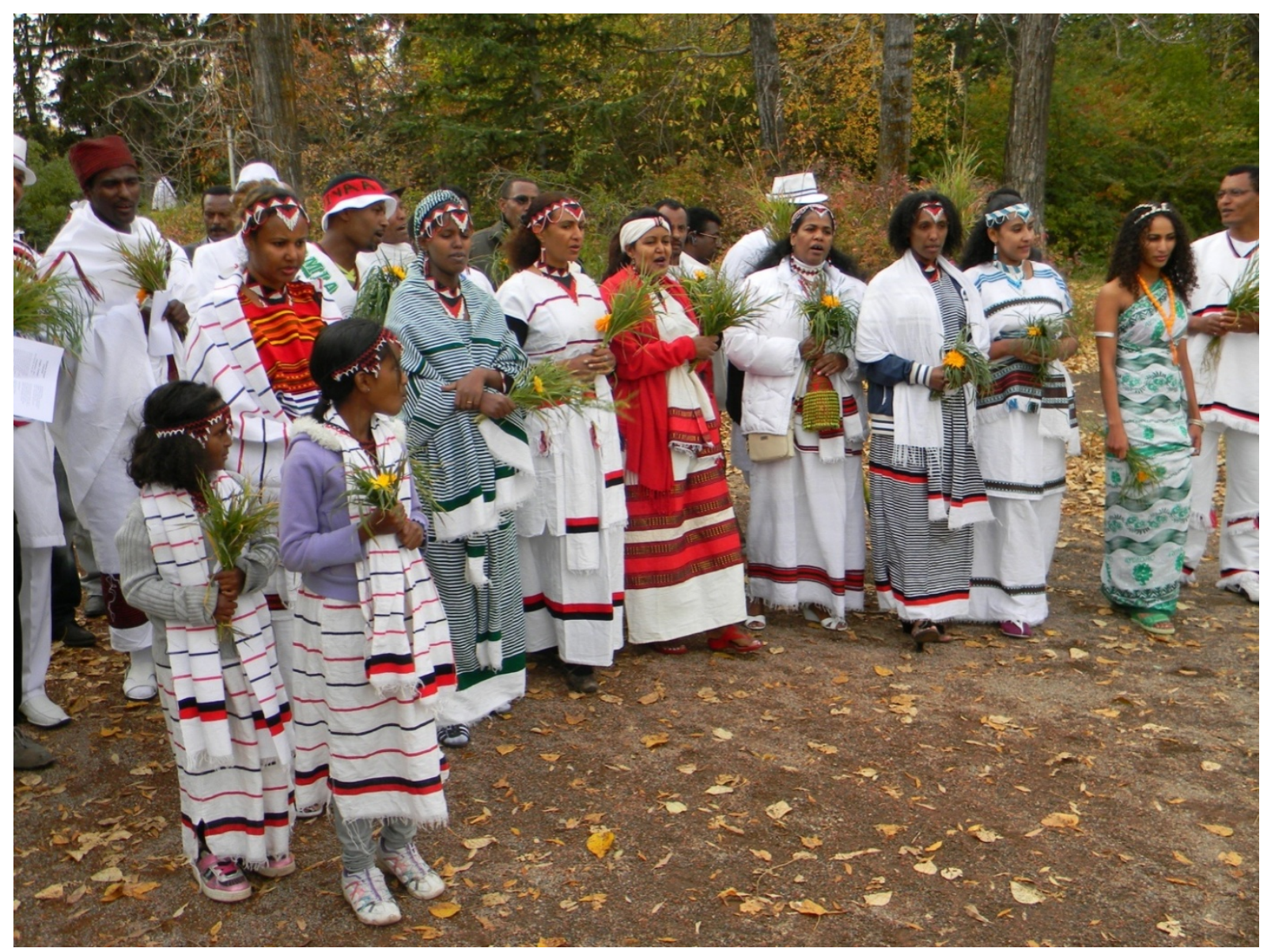

Figure 2. Calgary Oromo marching to the shore of the Bow River to celebrate Irreessaa

The social significance of the tuber continues among the diaspora Oromo, particularly in Nova Scotia, Canada, and in Minnesota and Tennessee, in the United States, where the tubers are grown. Anchote cultivation, dominated by Oromo women, creates a culturally perceived relationship between the women and anchote, which is upheld in the new communities. As well, several Oromo immigrants in North America and Europe reported transporting anchote to use on special occasions. (See Figure 2). 


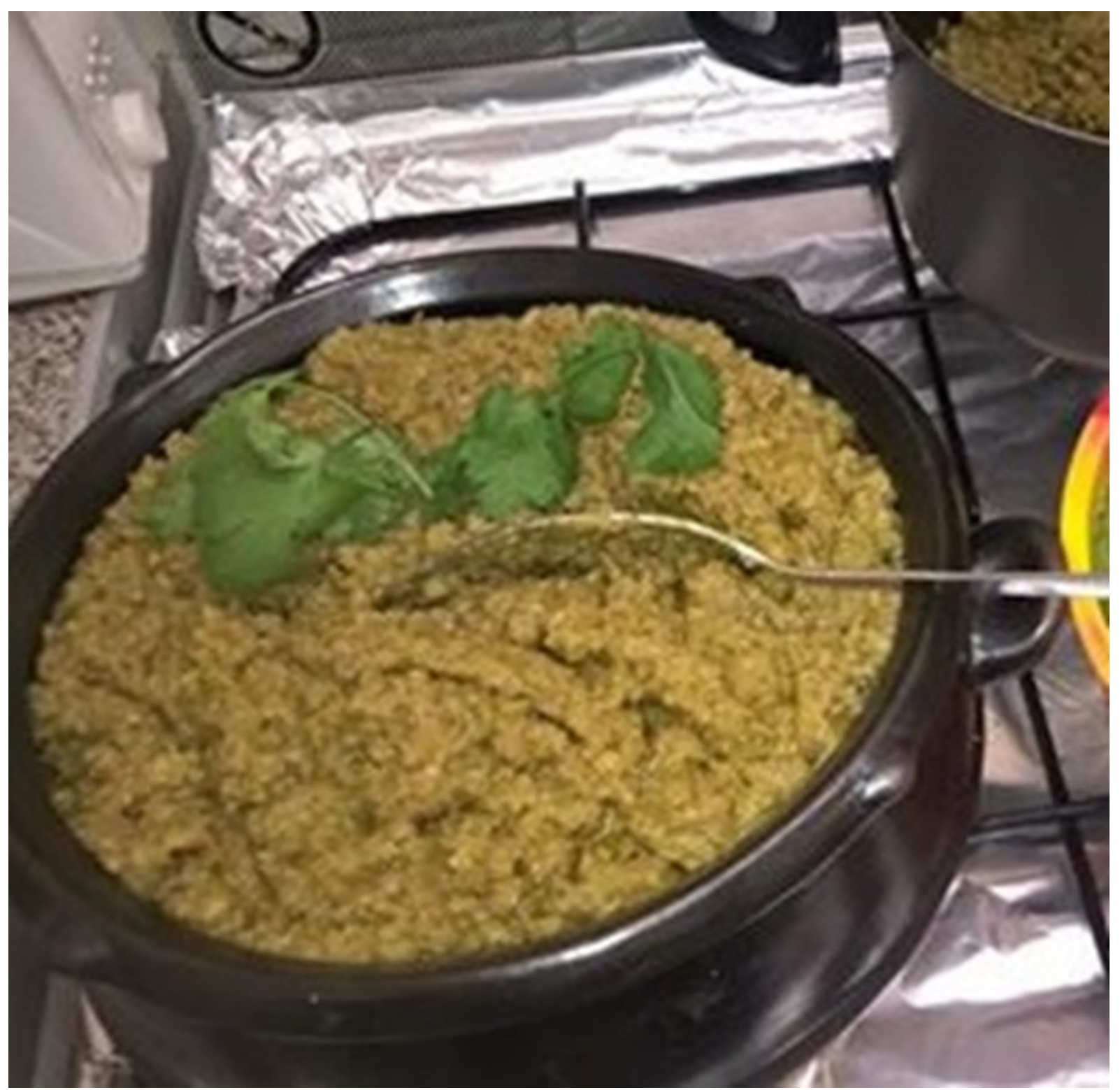

Figure 3. Anchote stew prepared for the Oromo Study Association Conference held in London, 2015.

Ethiopian-produced clothes and fabrics are another category of objects transported by the Oromo diaspora to North America. Most imported fabrics/clothes are owned by women and are viewed as vehicles of self-expression and conscious. The society also transmits social memory from one generation to the next through this material culture. The outfits have different colors, with black, red and white most prominent. Each color represents different Oromo age groups. The black represents those yet to enter active life: the youth. The red represents those in active life: the adults. Finally, the white represents those who have passed through active life: the elderly (Olam, 2003; Wayessa, 2015). Dressing in traditional multi-color clothes on certain occasions makes one beautiful and respectful. It is also a sign of good child-rearing practices, whereby the family has taught their children to embrace the tradition with love and joy. In this sense, a good family and good style are related. The non-human agents determine status in the society. This comes clear from the Oromo proverb, "warraa fi uffatatu nama xinneessa", which literally means, "family and clothes of a person determine his/her personality." Therefore, the Oromo dress in a certain way to meet their basic need for clothing and to confirm their identity. 


\section{Irreessaa festival: the meeting ground of 'communities' of people and things}

The Irreessaa festival is the Oromo Thanksgiving Day, during which the Oromo gather in sacred areas to thank Waaqa for the blessings and mercies received throughout the past year. The annual festival is celebrated throughout Oromia and in the Oromo diaspora at the beginning of Birraa (the sunny new season after the dark rainy winter season). Irreessaa is an event of gratitude to Waaqa, as well as a welcome to the new season of plentiful harvests after the rainy winter season. Friends, family, and relatives celebrate with joy and happiness, forging closer relationships and social bonds. At the time of celebration, the pilgrims carry bundles of green grass in their hands and place these bundles near Malkaa (rivers or lakes) (See Figure 4). A water body represents one of Waaqa's gifts and its continuous flow is equated with the continuity of lineages. The Oromo participate in this ceremony irrespective of their religious background.

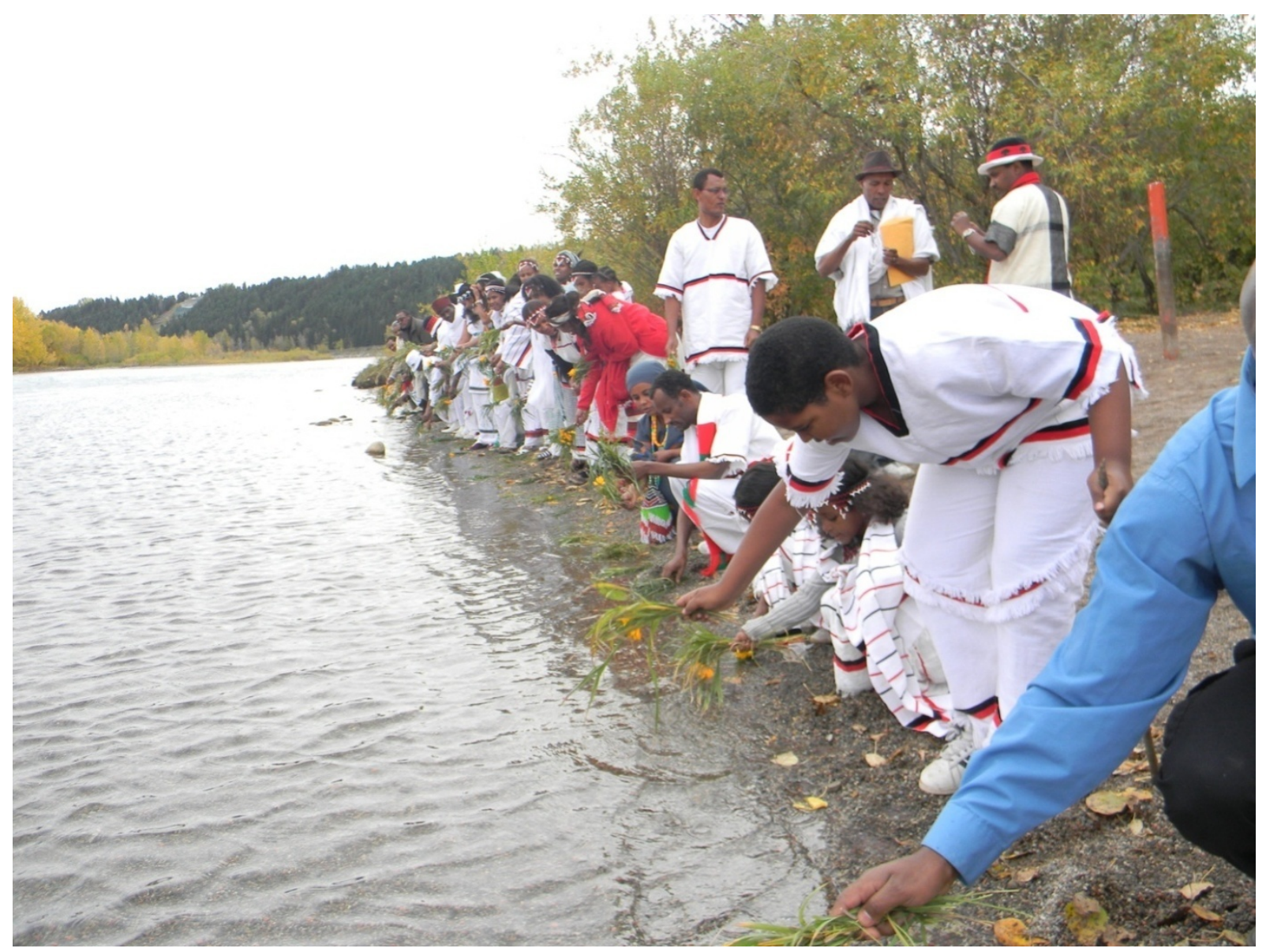

Figure 4. Calgary Oromo celebrating Irreessaa on the shore of the Bow River, Edworthy Park.

All age groups participate in the ceremony, as engaging in the traditional ways in North America ensures continuity of their practices and a means of overcoming their nostalgia. When individuals are dressed in traditional attire, they behave in an acceptable fashion; the clothes themselves frame their acts. The gathering also provides opportunity for people to share their experiences. The representations attributed to the traditional clothes, therefore, are believed to inform and constrain people's appearance and conduct. The color and designs of the cloth also inform outsiders about the group's identity and serve as social recognition. The gathering also sees households bringing traditional foods, including anchote, and holding a coffee ceremony (See Figure 5). 


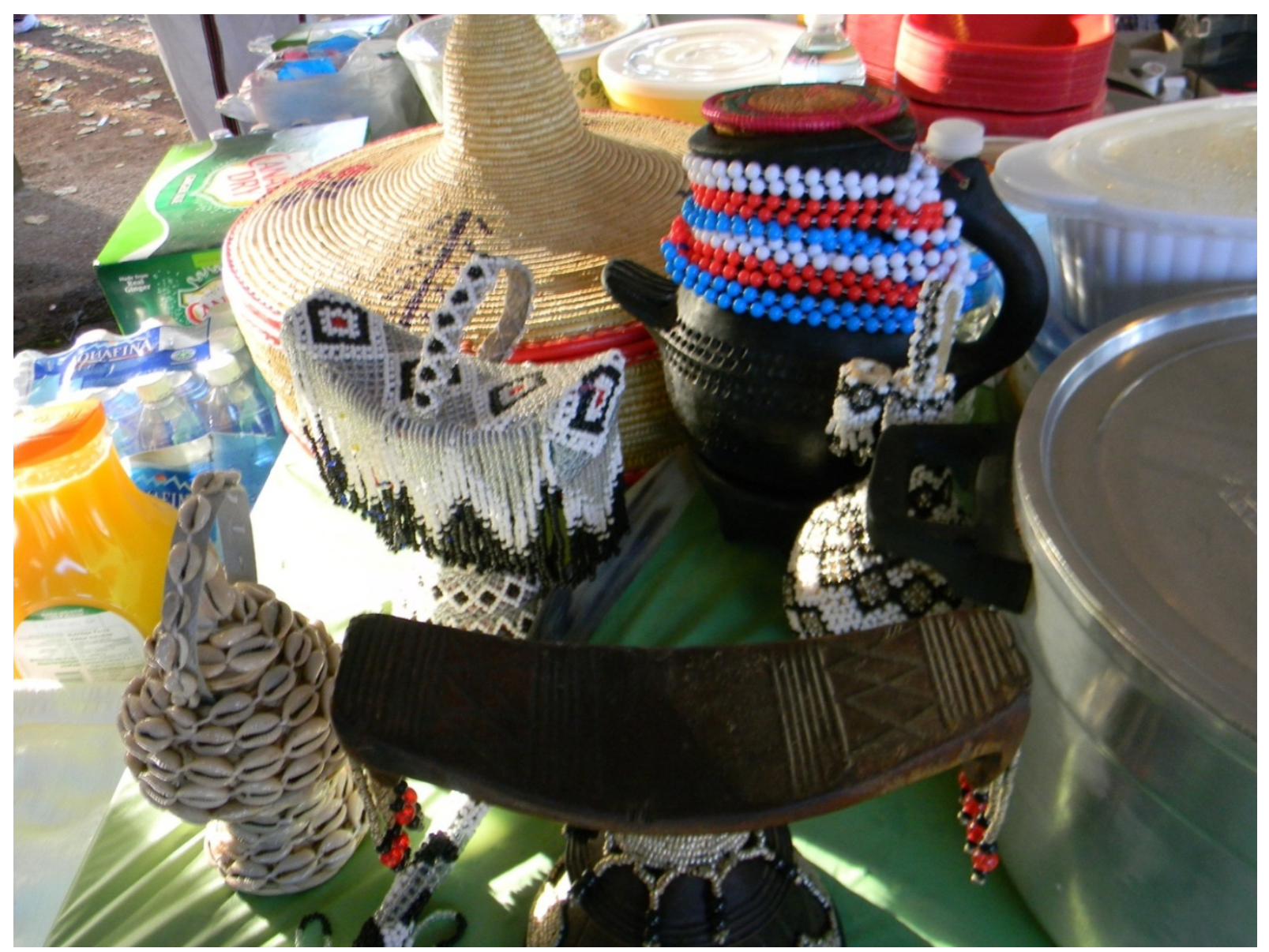

Figure 5. Oromo foods ready to be served at 2013 Irreessaa celebration, Edworthy Park Calgary.

Many researchers have illustrated that people's social identities are entangled with the objects that they produce and consume (Barrett, 2012; Dobres, 2000; Gell, 1998; Olsen, 2003, 2012; Knappett, 2012; Lyons, 2014; Miller, 2007; Robb, 2005; Sillar, 1996, 2004, 2009). The Oromo identity is affirmed by the objects that accompany them at the Irreessaa gathering. The objects are not passively enforcing the identity of the people but are institutionalizing their own existence by actively informing people that a colorful festival cannot exist without their presence. Through the negotiation between the two groups, the people also hold the idea that an Oromo gathering is comprises both human and non-human communities. According to Gosden (2005, p. 198), "material culture is relatively long-lasting; people are socialized into particular material worlds which exist prior to their birth." Lechtman (1984) also claims that objects represent local values and traditions. This implies that a child born in any given tradition learns about the tradition from humans and things that existed before the child's birth.

\section{Discussion and Conclusion}

This study examines people-things relationships in Oromo communities in North America and the role material cultures plays in connecting the immigrants in diaspora with one another and with their home country. The study shows that the Oromo worldviews are created and re-created by things-things, humanthings and human-human symbiotic relationships; essentially, people, objects and non-human organisms are interconnected. As well, objects and Oromo immigrants share special relationships that structure their co-existence. This concurs with a variety of anthropologists' perspectives (e.g., Downey, 2010; Knappett, 2012; Latour, 1999; Lyons, 2014). More important, the objects traveled with the people and, in the new destination, they interact actively with the humans through their agency. The objects give meaning to the diaspora social gatherings and, in so doing, participants retrieve and share memories and experiences stored in the accompanying objects. Their interactions with the objects also help them to find solace from nostalgia by connecting them to their home country. The same occurs at religious gatherings, whereby 
prayers are performed through the relationship of humans and objects. This implies that in the course of production, consumption and discard, objects are embodied and, thus, they actively engage in every-day interactions with their producers through their agency. Since most Oromo immigrants in North America are the first generation, the study only focused on this group. Knowledge about the second-generation's perception of the material objects of their parents' country of origin is limited. Future studies to investigate the changes in and continuity of the perceptions of the second generation about objects and the factors that inform these perceptions are worth conducting.

\section{Acknowledgements}

This study benefitted from the generous support of a number of people and an institution. I am very much grateful to the Oromo immigrants in North America among whom this study was conducted. I am also grateful to the Department of Anthropology and Archaeology of the University of Calgary for offering me a sessional position that gave me the opportunity to write this paper.

\section{References}

Abu-Ghazaleh, Faida N. (2013). Ethnic Identity of Palestinian Immigrants in the United States. E1 Paso, Texas: LFB Scholarly Publishing LLC.

Akhtar, S. (2005). Objects of our desire: Exploring our intimate connections with the things around us. New York, NY:Crown Publishing Group.

Aydin, H. \& Ozfidan, B. (2014). Perceptions on mother tongue based multicultural and bilingual education in Turkey. Multicultural Education Review, 6(1), 51-78.

Bourdieu, P. (1977).Outline of a Theory of Practice. Cambridge, UK: Cambridge University Press.

Bulcha, M. (2011).Contours of the Emergent \& Ancient Oromo Nation: Dilemmas in the Ethiopian Politics of State and Nation-building.Cape Town,South Africa: The Centre for Advanced Studies of African Society Press.

Caronia, L., and Mortari, L. (2015). The agency of things: how spaces and artefacts organize the moral order of an intensive care unit. Social Semiotics. 25,(4), 401-422.DOI: 10.1080/10350330.2015.1059576.

David, N., Sterner, J., and Gavua, K. (1988). Why pots are decorated. Current Anthropology.29, (3),365389.DOI: $10.1086 / 203649$.

DiCicco-Bloom, B., \& Crabtree, B. F. (2006). The qualitative research Interview. Medical Education.40, (4), 314-321.DOI: 10.1111/j.1365-2929.2006.02468

Dobres, M. A. (2000).Technology and Social Agency: Outlining a Practice Framework for Archaeology. Oxford, UK: Blackwell.

Dobres, M. A., and Robb, J. (2000). Agency in archaeology: Paradigm or platitude? In M. A. Dobresand J. Robb (Eds.), Agency in Archaeology(pp. 3-17).London, UK: Routledge.

Downey, G. (2010). "Practice without Theory": A neuroanthropological perspective on embodied learning.' For a special issue 'Making Knowledge'. Journal of the Royal Anthropological Institute. 16,(1), 22-40.DOI:10.1111/j.1467-9655.2010.01608.

Ehert, C. (2002).The Civilization of Africa: A History to 1800. Charlottesville, Virginia: University Press of Virginia.

Hassan, M. (1990).The Oromo of Ethiopia: A History 1517-1860. Cambridge, Cambridge: Cambridge University Press.

Graneheim, U.H and Lundman, B. (2004). Qualitativecontentanalysis innursing research:concepts, procedures and measure to achieve trustworthiness. Nurse Education Today.24, (2), 105-112. DOI: 10.1016/j.nedt.2003.10.001.

Gell, A. (1998).Art and Agency:an Anthropological Theory. Oxford, UK: Clarendon Press.

Giddens, A. (1984).The Constitution of Society. Cambridge, UK: Polity Press.

Greenberg, H. (1955). Studies in African Linguistic Classification. New Haven, CT: Compass Press.

Gosden, C. (2005). What do objects want? Journal of Archaeological Method and Theory.12, (3), 193211.DOI:10.1007/s10816-005-692.

Gosselain, O. (1999). In pots we trust: The processing of clay and symbols in Sub-Saharan Africa. Journal of Material Culture.4, (2), 205-230. DOI:10.1177/135918359900400205.

Kim, K. J. (2016). Interacting Socially with the Internet of Things (IoT): Effects of Source Attribution and Specialization in Human-IoT Interaction. Journal of Computer-Mediated Communication.21, (6), 420-435. DOI: $10.1111 /$ jcc4.12177. 
Knapett, C. (2014). Materiality in Archaeological Theory. In C. Smith (Ed.), Encyclopedia of Global Archaeology (Vol. 1, pp.4700-4706). New York. NY: Springer.

Knappett, C. (2012). Materiality. In Ian Hodder (Ed.), Archaeological Theory Today.(2 ${ }^{\text {nd }}$ ed.) pp.188-207. London, UK: Polity Press.

Kumsa, M. K. (2006). 'No! I'm not a refugee!'The poetics of be-longing among young Oromo in Toronto. Journal of Refugee Studies.19, (2), 230-255.DOI.org/10.1093/jrs/fel001.

Latour, B. (2005). Reassembling the Social-An Introduction to Actor-Network-Theory. Oxford: UK:Oxford University Press.

Latour, B. (1999).Pandora's Hope. Essays on the Reality of Science Studies. Cambridge, Massachusetts: Harvard University Press.

Lechtman, Heather N. (1984). Andean Value Systems and the Development of Prehistoric Metallurgy. Technology and Culture.25, (1),1-36. DOI: 10.2307/3104667.

Legesse, A. (1973).Gada: Three Approaches to the Study of African Society. London,UK: The Free Press.

Lyons, D. (2014). Perceptions of Consumption: Constituting Potters, Farmers and Blacksmiths in the Culinary Continuum in Eastern Tigray, Northern Highland Ethiopia. African Archaeological Review.31, (2), 169-201.DOI: 10.1007/s10437-014-9149-4.

Magersa, G. (1994).Knowledge, Identity and the Colonizing Structure: The Case of the Oromo in East and Northeast Africa (Doctoral dissertation). EThOS ID: uk.bl. ethos.361082.

McCracken, G. (1988). The long interview. Newbury Park, CA: Sage Publication.

Melba, G. (1988). Oromia: An Introduction to the History of the Oromo People. Minneapolis: MN: Lutheran University Press.

Olam, G. Belay G. (2003).Contextualizing the Church among the Muslim Oromo (Doctoral dissertation). UMI no.:3102612.

Olsen, B. (2003). Material culture after text: re-membering things. Norwegian Archaeological Review. 36, (2), 87-104. DOI: 10.1080/00293650310000650.

Servan, B. M. (2008).Sacred networks Religion and social life among Oromo in Norway (Master's Thesis). Retrieved from http://bora.uib.no/bitstream/handle/1956/3029/45614990.pdf? sequence $=1 \&$ is Allowed $=y$.

Sillar, B. (1996). Playing with God: cultural perception of children, play and miniatures in the Andes. ArchaeologicalReview from Cambridge.13, (2), 47-63.

Sillar, B. (2004). Acts of God and active material culture: agency and commitment in the Andes. In A. Gardner (Ed.), Agencyand Archaeology (pp. 153-209). London, UK: UCL Press.

Sillar, B. (2009). The Social Agency of Things? Animism and Materiality in the Andes. Cambridge Archaeological Journal. 19, (3), 367-377.DOI:10.1017/S0959774309000559

Ta'a, T.(2006). The political economy of an African society in transformation: the case of Macca Oromo (Ethiopia).Otto Harrassowitz, Berlin: Humboldt University Press.

Van Oenen, G. (2011). Interpassive agency: engaging actor-network-theory's view on the agency of objects. Theory \& Event. 14, (2), 1-19. DOI: 10.1353/tae.2011.0014.

Wayessa, Bula S. (2016).Toward a history of the Oromo of Wallaga in southwestern Ethiopia: an ethnoarchaeological study of ceramic technological style and tuber crop domestication (Doctoral Dissertation). Available from ProQuest Dissertations \& Theses Global database (DOI:10.13140/RG.2.1.4823.2729).

Wayessa, Bula S. (2015) "Say let it be spared from eyes for a ware cannot survive eyes:" Personification of pots among Oromo of Wallagga, Ethiopia. Journal of Social Archaeology.15, (3), 387-407.DOI: $10.1177 / 1469605315589021$

Wayessa, Bula S., Lyons, D., and Kooyman, B. (2015). Ethnoarchaeological Study of Brewing Technology in Wallaga Region of Western Oromia, Ethiopia. Journal of African Archaeology.13,(1), 99-114. DOI: $10.3213 / 2191-5784-10268$. 